\title{
Experimental and Numerical Study of Water Mist Fire Suppression System Effectiveness on Shielded Fire
}

\author{
Kuswantoro $^{1}$, Y.S.Nugroho ${ }^{1, *}$ \\ ${ }^{1}$ Fire Safety Engineering Research Group, Mechanical Engineering Department, University of Indonesia, Kampus UI Depok 16424, \\ Indonesia
}

\begin{abstract}
This study aims to investigate the effectiveness of water mist on suppressing a

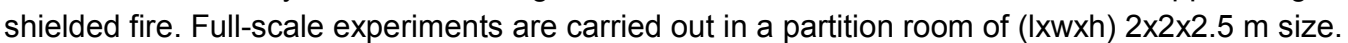
Five water mist nozzle which consist of two type nozzle was used, high flow (fogjet) nozzle installed at top center of the room and fine spray nozzle installed at each side of room at high 1.5 $\mathrm{m}$ from ground. The pressure of water mist system was maintained at 20 bar which correspond to $2.6 \mathrm{lpm}$ of water flow rate. Wood crib of $6.5 \times 6.5 \times 6 \mathrm{~cm}$ size was used as the fuel source. The obstruction used as a fuel shield has table like form with $40 \times 40 \mathrm{~cm}$ cover area and $0.5 \mathrm{~m}$ height. The location of fuel source and fuel shield was varied (1) fuel source and shield at centre of room, (2) fuel source at one side of shield and the shield at centre of room, (3) fuel source and shield at corner of room, and (4) ) fuel source at one side of shield and the shield at corner of room. Numerical simulation using FDS 6.5.3 was also performed to validate the use of FDS and get better understanding of the phenomena. The results showed that water mist was able to extinguish the fire around $20 \mathrm{~s}, 16 \mathrm{~s}, 30 \mathrm{~s}$, and $24 \mathrm{~s}$ for scenario 1, 2, 3 and 4 respectively. It is also observe that the mist distribution around the shield and cover area of the shield play a role on the capacity and time needed of water mist to extinguish the fire.
\end{abstract}

\section{Introduction}

Typically the design of material storage system of a warehouse is to store materials on pallets rack or stack vertically. Because of it a warehouse usually has high fire hazard and the fire is difficult to handle especially if the fire start at a location that is shielded from water droplet of fire suppression system. Fire safety improvement for warehouse can be achieved by providing fast response and effective fire suppression system such as water mist system. Based on the droplet sizes, the water-based fire suppression systems can be classified into the sprinkler system and the water mist system. The sprinkler system usually suppresses the fire through the direct cooling of fire source and thermal plume with relatively larger droplet size. Water mist has been acknowledged for the effectiveness on suppressing and extinguishing on several type fires with minimum water damage and water consumption due to the small droplet size $(<1.000 \mu \mathrm{m})$. The suppression mechanism by using water mist as fire suppression involve several combined physical phenomena which is [1] :

- Gas phase cooling, removal of heat from the combustion zone due to evaporation of water

- Oxygen depletion, the production of steam can significantly reduce the oxygen concentration

- Wetting and cooling, reduces the pyrolysis or gasification rate of the fuel
- Radiation attenuation, Water mist and water vapor reduce radiant heat flux to objects near the fire, which assists in preventing fire spread to unburned fuel

- Kinetic effect, diluents of water vapor and gas, spoil or impair the efficiency of combustion reaction

Many researches have been made to study the water mist system, according to the fuel source enclosure some of them are the following.

\subsection{Unshielded Fire}

Fitri Pancawardani et all [2] conducted experiment and numerical study of low pressure water mist fire suppression system for wood crib/ cellulose material of $12 \times 12 \times 27 \mathrm{~cm}$ size as the fuel material. The experiment system pressure and flow rate was 3, 5 and 7 bar $0.15,0.19$, and $0.23 \mathrm{lpm}$ respectively. The results showed that water mist spray can extinguish the fire effectively under $28 \mathrm{~s}$, with 7 bar system pressure as the fastest. At higher water pressure, water mist can cover larger fuel surface and perform cooling action, to prevent fuel vapor from reacting with oxygen.

A. Jenft et all [3] studied water mist application to a pool fire by experiments in a real-scale room and numerical method. A $35 \mathrm{~cm}$ cylindrical pool was used,

\footnotetext{
Corresponding author: yulianto.nugroho@ui.ac.id
} 
with a heat release rate $75 \mathrm{~kW}$. The nominal flow rate on the water mist was $25 \mathrm{l} / \mathrm{min}$ provided by a set of four nozzles, injecting droplets with mean Sauter diameter equal to $112 \mu \mathrm{m}$. Observations of fire suppression shows a fast suppression (10 s) when water mist was applied to a developed fire and slower suppression (1 min) when applied early.

\subsection{Shielded Fire}

Chen-Wei Chiu and Yu-Hsiu Li [4] conducted 8 scenario of full-scale fire experiments and numerical simulations to study the effectiveness of water mist to unexposed fire sources of wind generator. Diesel fuel was used as fire source on $44.7 \times 44.7 \mathrm{~cm}, 63.3 \times 63.3 \mathrm{~cm}$, and $77.5 \times$ $77.5 \mathrm{~cm}$ drain pan. Based on the drain pan dimension, the approximate HRR was $420 \mathrm{~kW}, 800 \mathrm{~kW}$ and 1.3 MW respectively. The experiment used two special design water mist nozzle with operating pressure of 100 bar and flow rate of $13.5 \mathrm{lpm}$ from single nozzle. The experimental studies show that water mist system capable of extinguishing fire within 2 minute for shielded fire located in the middle and 5 minute for shielded fire in the corner.

\section{Experiment Setup}

A partition room constructed of hollow bar and calcium silicate board with dimension of (lxwxh) $2 \times 2 \times 2.5 \mathrm{~m}$ was utilized as the enclosure. No windows provide in the room and the only ventilation available was a full opening at top of a room. The obstruction used as a fuel shield has shape like table which made from metal sheet with $4 \mathrm{~mm}$ thickness, $40 \times 40 \mathrm{~cm}$ cover area and $0.5 \mathrm{~m}$ leg height. . Wood crib of $6.5 \times 6.5 \times 6 \mathrm{~cm}$ size was utilized as the fuel source. It made from ice cream stick and consist of 22 layer, each layer consist of 3 stick which give total 66 stick. A pretest burning was perform to see the burning process (figure 2(c)). The burning start from the top layer and to accelerate and maintain the burning, gasoline was applied at the 6 top layers.

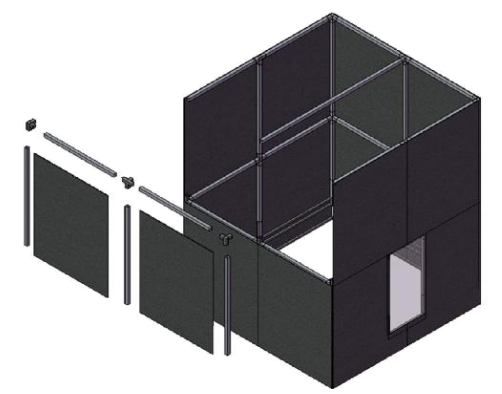

(a)

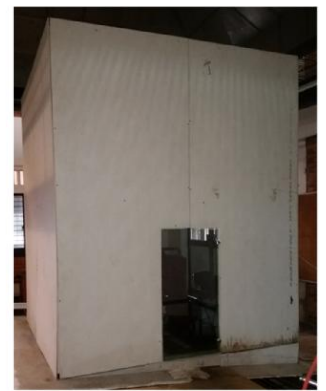

(b)
Fig. 1. (a) Model design and (b) image of partition room

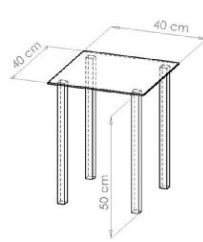

(a)

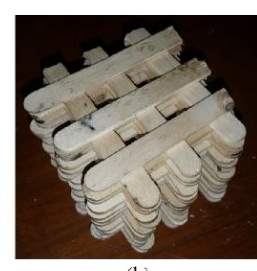

(b)

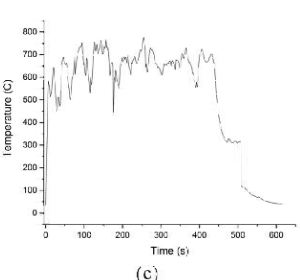

(c)
Fig. 2. (a) fuel shield, (b) fuel source, (c) average temperature of pretest burning of fuel

Five water mist nozzle which consist of two type nozzle was used, high flow (fogjet) nozzle installed at top center of the room and fine spray nozzle installed at each side of room at high $1.5 \mathrm{~m}$ from ground. At pressure of 20 bar the fogjet deliver $1.78 \mathrm{lpm}$ of water flow rate and single fine spray nozzle deliver $0.21 \mathrm{lpm}$ of water flow rate which give total flow rate of $2.62 \mathrm{lpm}$.

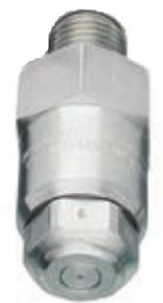

(a)

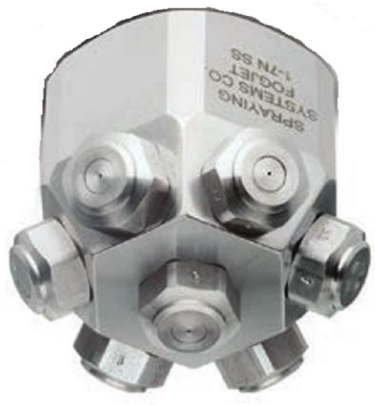

(b)
Fig. 3. (a) Fine spray nozzle, (b) fogjet nozzle

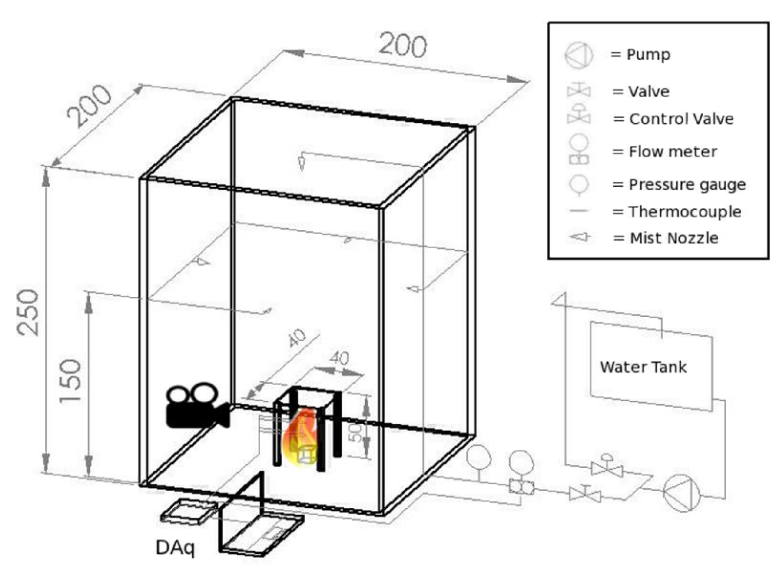

Fig. 4. Schematic of experiment setup

Measurement devices used in this study were $\mathrm{K}$ type thermocouple (placed at $4 \mathrm{~cm}$ and $10 \mathrm{~cm}$ above the fuel source), pressure gauge and positive displacement flow meter, figure 4 show the complete schematic of the experiment setup.

\section{Shielded Fire Scenario}

To investigate the effectiveness of water mist on suppressing a shielded fire, this study uses various fuel placements. Water mist flow rate and activation time maintain at $2.6 \mathrm{lpm}$ and $60 \mathrm{~s}$ after ignition, table 1 list all the scenario and figure 5 illustrate the top view of the scenario. 
Table 1. Shielded fire scenario

\begin{tabular}{|c|c|c|}
\hline Scenario & $\begin{array}{c}\text { Fuel shield } \\
\text { placement }\end{array}$ & $\begin{array}{c}\text { Fuel source } \\
\text { placement }\end{array}$ \\
\hline scenario 1 & center of the room & center of the shield \\
\hline scenario 2 & center of the room & side of the shield \\
\hline scenario 3 & corner of the room & center of the shield \\
\hline scenario 4 & corner of the room & side of the shield \\
\hline
\end{tabular}

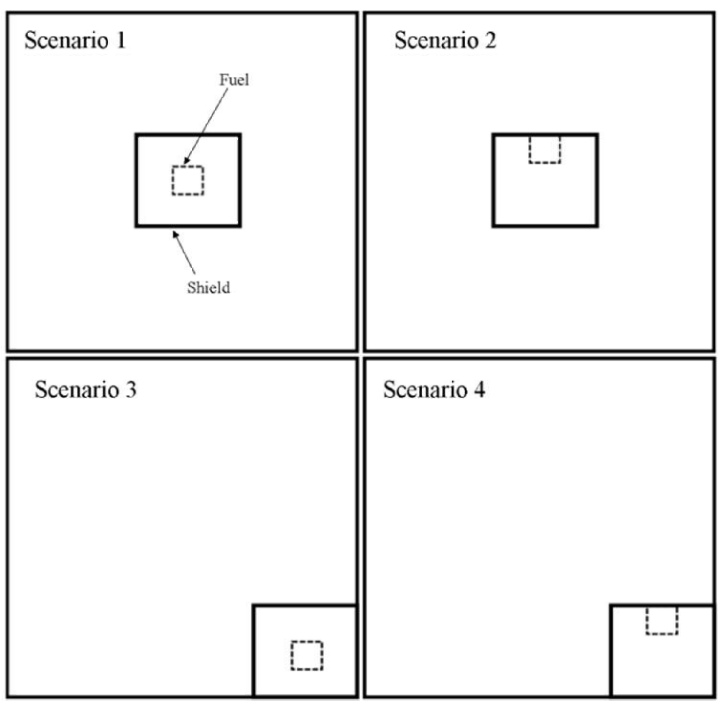

Fig. 5. Top view of the scenario

\section{Numerical Setup}

The numerical analysis conducted using Fire Dynamic Simulator (FDS) version 6.5.3. FDS is a Computational Fluid Dynamic (CFD) software for fire driven flow develop by National Institute of Standards and Technology (NIST). FDS calculation base on NavierStokes equation, continuity, momentum, energy and gas species composition as follow [5] (equation 1 to 4):

$\frac{\partial \rho}{\partial t}+\nabla \cdot(\rho \vec{V})=0$

$\frac{\partial \rho \vec{V}}{\partial t}+(\rho \vec{V} \cdot \nabla) \vec{V}=\rho \vec{F}-\nabla \mathrm{P}+\mu \mathrm{V}^{2} \vec{V}+\frac{\mu}{3} \nabla(\nabla \cdot \vec{V})$

$\rho \frac{\partial e}{\partial t}(\rho \vec{V} \cdot \nabla) e=-P \nabla \cdot \vec{V}+\nabla \cdot(\mathrm{k} \nabla \mathrm{T})+\rho \dot{q}+\phi$

$\frac{\partial \rho Y_{l}}{\partial t}+\nabla \cdot\left(\rho Y_{l} \vec{V}\right)=\nabla \cdot\left(\rho D_{l} \nabla Y_{l}\right)+\dot{\mathrm{m}}^{\prime \prime \prime}$

\subsection{Geometry and Mesh Size}

The modeled geometry of the FDS for shielded fire experiment shown in figure 6. The dimensions were exact as specified in figure 4 except the number of thermocouple used in the simulation was 9 to capture the flame temperature. One of the factor influence the accuracy of FDS analysis is the mesh dimension. The smaller the mesh size, the higher its accuracy with higher computational time needed. To determine the mesh size $(d x)$, it's usually needed to calculate characteristic fire diameter $\left(D^{*}\right)$ using the following relationship [6]: $\begin{aligned} D^{*} & =\left(\frac{\dot{Q}_{f}}{\rho_{\infty} c_{p} T_{\infty} \sqrt{g}}\right)^{\frac{2}{5}} \\ d x & =\frac{D^{*}}{10}\end{aligned}$

$d x=\frac{D^{*}}{10}$

Since the HRR relatively small compare to the computational domain, in order to reduce the number of the mesh, multiple mesh was defined with $d x=0.1 \mathrm{~m}$ except for the mesh under the shield with $d x=0.0125$ $\mathrm{m}$ (calculated from equation (5) and (6)).

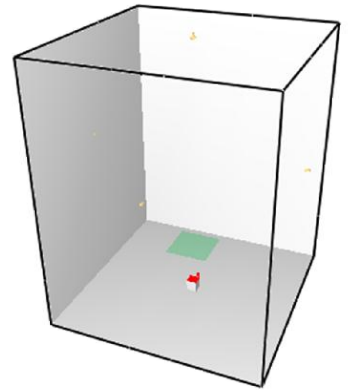

(a)

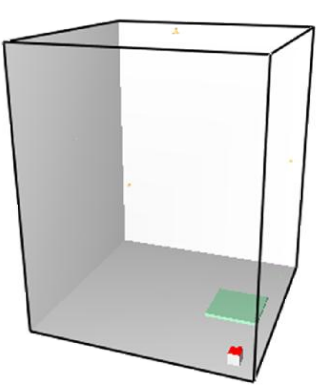

(b)
Fig. 6. FDS model of shielded fire experiment (a) scenario 1 (b) scenario 3

\subsection{Heat Release Rate and Combustion}

Fire was defines as a simple fire from surface with HRRPUA of $400 \mathrm{~kW} / \mathrm{m}^{2}$ over $0.01 \mathrm{~m}^{2}$ surface. The HRR pattern was specified as linear ramps from 0 to 240 $\mathrm{kW} / \mathrm{m}^{2}$ and 240 to $400 \mathrm{~kW} / \mathrm{m}^{2}$ in 0 to $1 \mathrm{~s}$, and 1 to $20 \mathrm{~s}$ respectively. Single step, mixing controlled combustion was used to model the combustion with fuel define as $\mathrm{C}_{6} \mathrm{H}_{10} \mathrm{O}_{5}$, and $0.005 \mathrm{CO}$ yield which correspond to the stoichiometry coefficient as follow.

$$
\mathrm{C}_{6} \mathrm{H}_{10} \mathrm{O}_{5}+5.98 \mathrm{O}_{2} \rightarrow 5.97 \mathrm{CO}_{2}+0.03 \mathrm{CO}+5 \mathrm{H}_{2} \mathrm{O}
$$

\subsection{Extinction Parameter}

FDS extinction model are based on the concept of a critical flame temperature and auto ignition temperature. The default critical flame temperature $1327^{\circ} \mathrm{C}$ was used in this study and for auto ignition temperature it is set at $240{ }^{\circ} \mathrm{C}$ [7]. It is also define the e_coefficient of the fire $320 \mathrm{~m}^{2} \mathrm{~s} / \mathrm{kg}$.

\subsection{Ignition}

Because the use of auto ignition temperature above $0{ }^{\circ} \mathrm{C}$, the fuel gas need an air with temperature above the auto ignition temperature to produce flame. For this purpose, it is define a small obstruction (igniter) above the fuel with surface temperature $1000{ }^{\circ} \mathrm{C}$. This igniter was set to turn off if temperature on the thermocouple reach 300 ${ }^{\circ} \mathrm{C}$.

\subsection{Water Mist}

The water mist defines as full cone nozzle with spray angle $100^{\circ}$ for fine spray nozzle and $75^{\circ}$ for fogjet 
nozzle. The droplet distribution used Rosin-Rammlerlognormal with diameter of 10 to $500 \mu \mathrm{m}$ as specified in nozzle manufacture datasheet [8]. The number of nozzle and water flow rate was same as the experiment describe in subchapter 2 except for the fogjet it was modeled as 7 nozzles with various orientation.

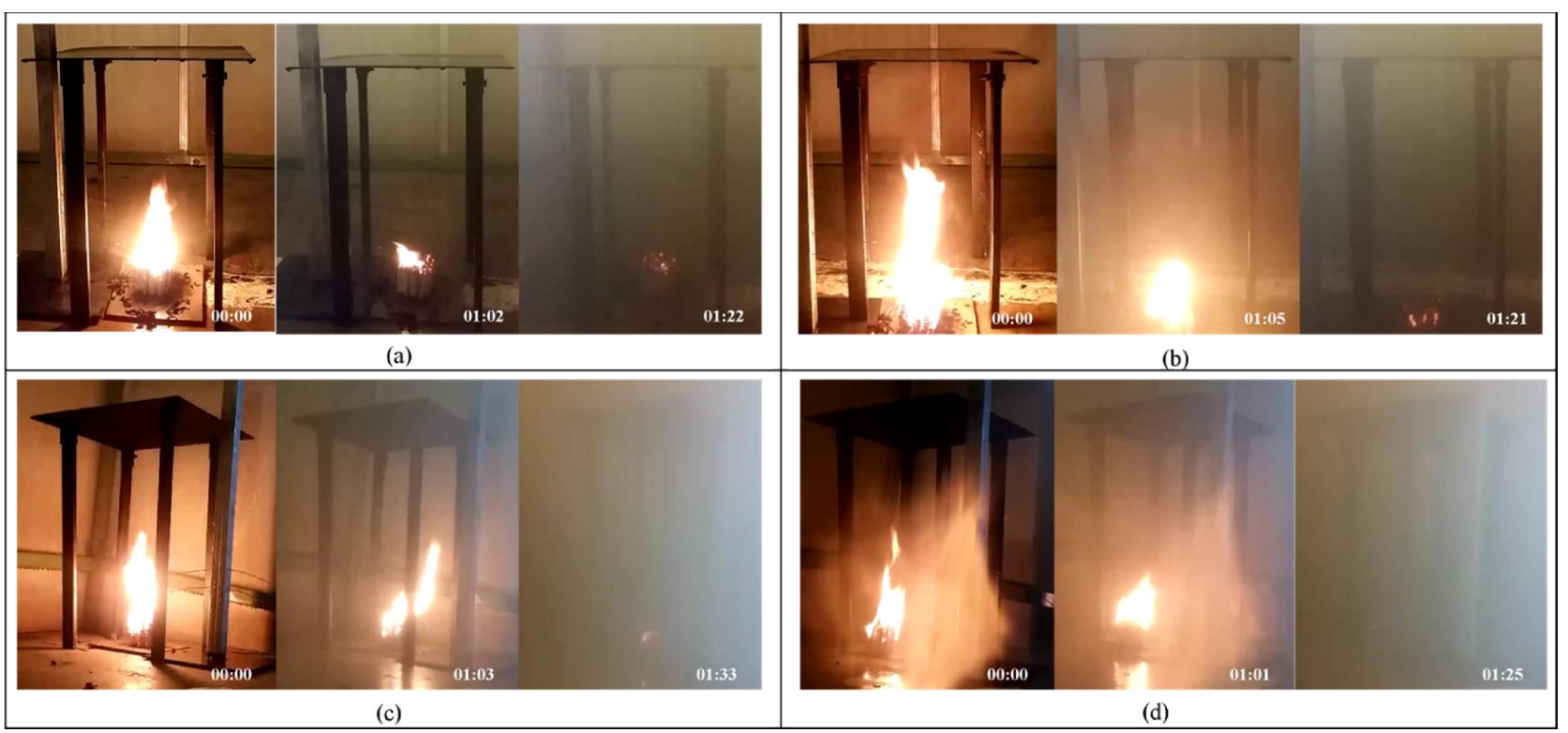

Fig. 7. Video Snapshoot (a) scenario 1, (b) scenario 2, (c) scenario 3, (d) scenario 4

\section{Results and Discussion}

\subsection{Water Mist Distribution}

Water mist distribution was measured by placing $20 \times 20$ cups on the floor with fuel shield installed on the middle of the room. The system run for 10 minutes and the water in the cups was measured in milliliters which then converted to mass base by assuming water density of $997 \mathrm{~kg} / \mathrm{m}^{3}$. The results were used as information of distribution pattern and validation of FDS water mist model.

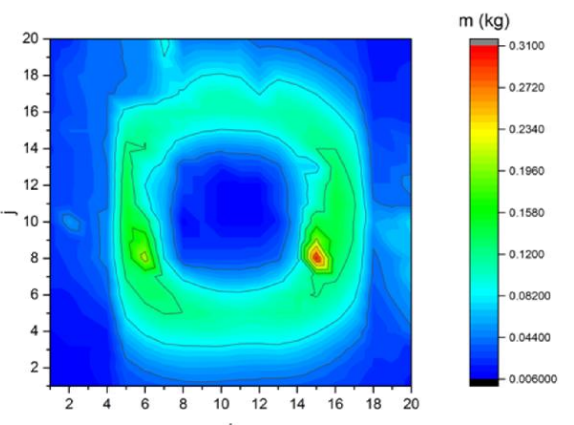

(a)

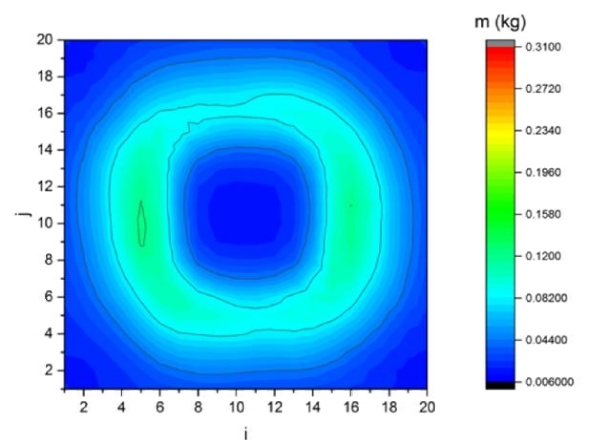

(b)

Fig. 8. Water mist distribution of (a) experiment and (b) FDS

Figure 8, show the result of the experiment and FDS of the water mist pattern distribution on the floor. There is a good agreement between experiment and simulation where there is an area with high concentration around the shield but in the experiment there is high spot concentration due to the fact that the experiment floor has inclination of $5^{\circ}$ and imperfect installation. 


\subsection{Experiment Result}

Figure 7 and 9 respectively shows the video snapshoot of the experimental work and flame temperature. As can be seen from figure 9 there is different on the maximum temperature and also the increase rate of temperature of the development phase for each scenario with scenario 3 as the highest. Perhaps this temperature profile different cause by non uniformity in the fuel source. It is also observe after the water mist activated, there is a slightly increase of temperature just before the mist contact with the fire then follow by suppression. Figure 7 shows the video snapshoot of the experimental work at ignition $(t \approx 0 s)$, water mist activation $(t \approx 60 s)$ and extinction. From figure 7, the time needed of water mist to extinguish the fire was around $20 \mathrm{~s}, 16 \mathrm{~s}, 30 \mathrm{~s}$, and 24 $\mathrm{s}$ for scenario 1, 2, 3 and 4 respectively. Base on the fuel shield placement (centre and corner of the room) the comparison of the result between scenario 1 and 3 and between scenario 2 and 4 shows that the mist distribution around the shield affects the time needed to extinguish the fire, the higher the mist distribution the faster the extinguishment process. Base on the fuel source placement relative to the shield (centre and side of the shield), the comparison of the result between scenario 1 and 2 and also between scenario 3 and 4 shows that cover area of the shield on the fuel source had a role on time needed to extinguish the fire.

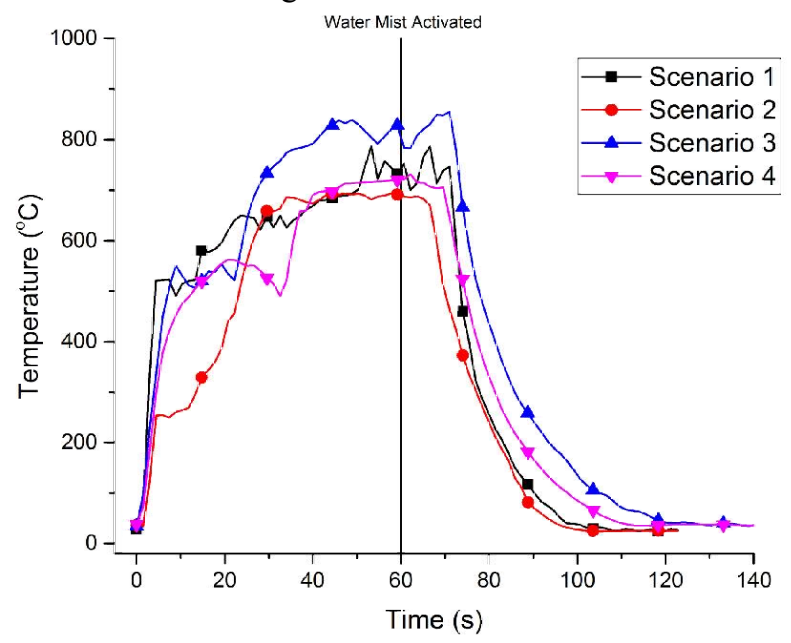

Fig. 9. Thermocouple temperature

\subsection{Simulation Result}

The introduction of water mist into the room creates vortex that mix water droplet with fire plume and cool the room temperature. Figure 10 (a) and (b) respectively shows flow vector color weighted by water mass of FDS for scenario 1 and 3 several second after the water mist system activated. In both scenarios it can be seen that the water droplet reach the flame from the side after taking curve path.
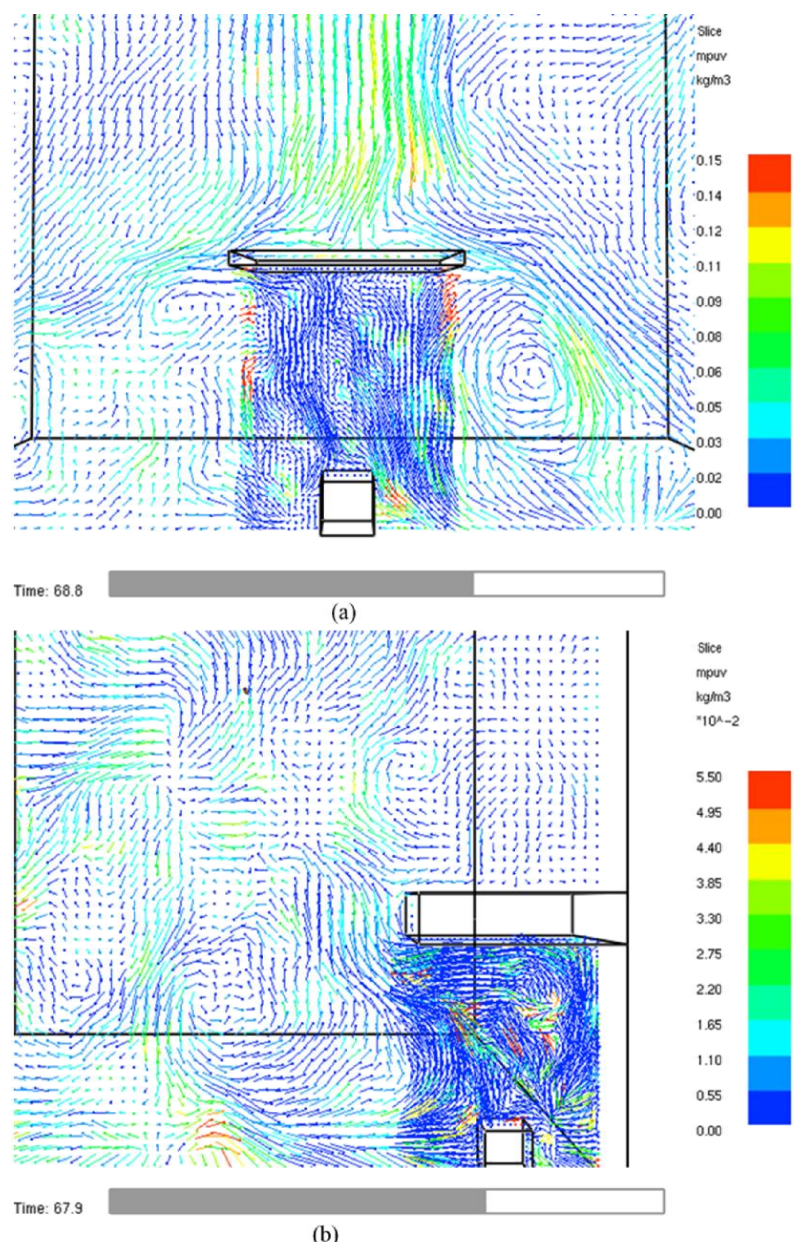

Fig. 10. Flow vector color weighted by water mass for scenario 1 and 3

Figure 11 (a) and (b) respectively shows comparison of experiment and FDS flame temperature for scenario 1 and scenario 3. It is show there is difference in temperature profile for both scenario which maybe cause by the use of multiple mesh with different grid size, however overall it is show that FDS was capable of performing simulation of water mist suppression on shielded fire. 


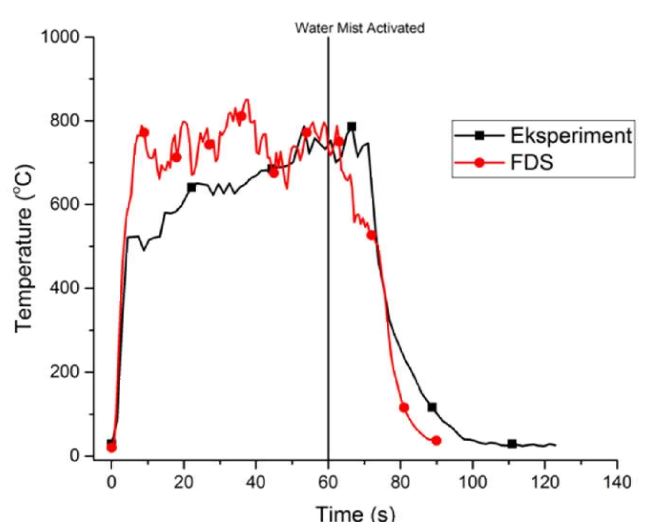

(a)

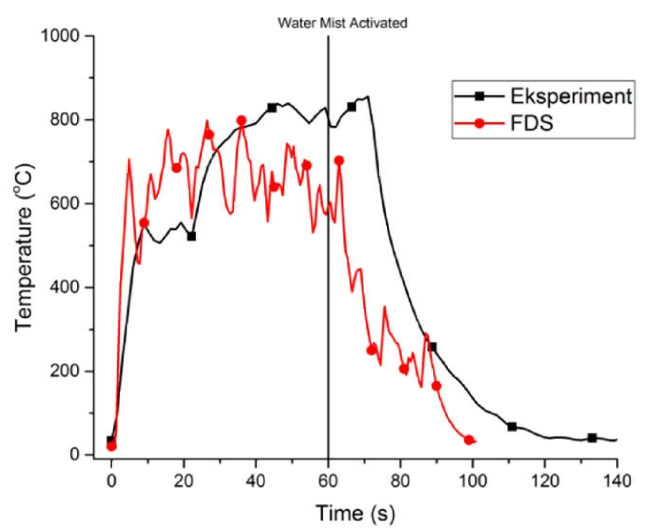

(b)

Fig. 11. Experiment and FDS temperature comparison for (a) scenario 1 and (b) scenario 3

\section{Conclusions}

The results of a series of experiments on shielded fire suppression using water mist show the capacity of water mist to extinguish shielded fire. The mist distribution around the shield affects the time needed to extinguish the fire, the higher the mist distribution the faster the extinguishment. Cover area of the shield on the fuel source also had a role on the capacity and time needed to extinguish the fire. Numerical simulation of the experiment shows the capacity of FDS for simulation of water mist fire suppression on shielded fire. The time needed of water mist to extinguish the fire was around $20 \mathrm{~s}, 16 \mathrm{~s}, 30 \mathrm{~s}$, and $24 \mathrm{~s}$ for scenario 1, 2, 3 and 4 respectively.

The authors would like to thank Pemerintah Provinsi DKI Jakarta, Indonesia for the scholarship given to Mr. Kuswantoro and Dinas Penanggulangan Kebakaran dan Penyelamatan DKI Jakarta for great discussion and their support.

The authors are also greatful with research grant provided by the Ministry of Research, Technology, and Higher Education of the Republic of Indonesia and Universitas Indonesia through the Penelitian Terapan Unggulan Perguruan Tinggi (PTUPT) 2018 program with contract number 514/UN2.R3.1/ HKP05.00/2018.

\section{Reference}

[1] J. R. Mawhinney and G. G. Back, "Water Mist Fire Suppression Systems," in SFPE Handbook of Fire Protection Engineering, 2016, pp. 1590-1593.

[2] F. Pancawardani, D. Arini, R. Putra, M. Lutfi, and F. Ali, "Analysis of Water Mist Fire Suppression System Applied on Cellulose Fire," Procedia Eng., vol. 170, pp. 344-351, 2017.

[3] A. Jenft, A. Collin, P. Boulet, G. Pianet, A. Breton, and A. Muller, "Experimental and numerical study of pool fire suppression using water mist," Fire Saf. J., vol. 67, pp. 1-12, 2014.

[4] C. Chiu and Y. Li, "Full-scale experimental and numerical analysis of water mist system for sheltered fire sources in wind generator compartment," Process Saf. Environ. Prot., vol. 98, pp. 40-49, 2015.

[5] K. Mcgrattan, S. Hostikka, R. Mcdermott, J. Floyd, C. Weinschenk, and K. Overholt, Fire Dynamics Simulator Technical Reference Guide Volume 1: Mathematical Model, Sixth Edit., vol. 1. NIST, 2017.

[6] K. Mcgrattan, S. Hostikka, R. Mcdermott, J. Floyd, C. Weinschenk, and K. Overholt, Fire Dynamics Simulator User 's Guide, Sixth Edit. NIST, 2017.

[7] D. K. Shen, M. X. Fang, C. Energy, W. K. Chow, and H. Kong, "A Review on Ignition of Cellulose Materials Under External Heat Flux," Int. J. Eng. Performance-Based Fire Codes, vol. 8, no. 1, pp. 28-42, 2006.

[8] Spraying System Co., "Industrial Hydraulic Spray Products Catalog.” p. E6. 